\title{
Bipolar Plasma Kinetic Vaporization Resection in the Management of Benign Anastomotic Stricture after Rectal Cancer Surgery: A Report of 12 Cases
}

\section{Shaopeng Zhang}

Jilin University First Hospital

Mingming Xiao

Jilin University First Hospital

\section{Song Wu}

Jilin University First Hospital

guoqiang pan

Jilin University First Hospital

yuan kong

Jilin University First Hospital

wei li ( $\nabla$ weili8308@jlu.edu.cn )

Jilin University First Hospital https://orcid.org/0000-0002-9074-4649

\section{Research}

Keywords: Prostate vaporization, Rectal cancer, Anastomotic stricture, Case report

Posted Date: September 21st, 2021

DOI: https://doi.org/10.21203/rs.3.rs-903375/v1

License: (c) (i) This work is licensed under a Creative Commons Attribution 4.0 International License. Read Full License 


\section{Abstract}

Background: Postoperative anastomotic stricture is a common complication after kinds of rectal cancer surgery, especially in low anterior resection and anal retention patients. Currently, various of treatments including anal expansion, endoscopic dilation and also surgery are applied with different efficacy and safety. Besides, bipolar plasma kinetic vaporization resection is a technique used to be applied for benign prostatic hyperplasia with minimally invasion and high safety. To the best of my knowledge, it had not been reported to be applied for narrow scars after rectal surgery.

Methods: To analysis retrospectively the clinical data of 12 patients who suffered anastomotic strictures after rectal cancer surgery in the First Hospital of Jilin University from Feb 2015 to December 2017.

ResultखAll of them were successfully treated by the technique of once bipolar plasma kinetic vaporization resection in 8 cases, twice in 3 cases, and more times in 1 cases without occurrence of additional complications.

Conclusions: Demonstrated by these limited cases, bipolar plasma kinetic vaporization resection would be applied as an alternative method in the treatment of postoperative anastomotic strictures due to its advantages as well as its effectiveness and safety.

\section{Introduction}

Open and lapaosscopic abdominoperineal resection of rectal cancer is regarded as a standard surgical method for a long time[1]. With the development of treatment permanent stoma is declined over time, and immediate resection and anastomosis even for low rectal cancer has increased[2]. The incidence of postoperative anastomotic strictures after rectal surgery was reported to be different due to different definitions, population and surgery in previous studies. An overall estimate of stricture rate was approximately 5 to $9 \%$ after hand-sewn anastomosis, while increased rate of stricture after stapled anastomosis [3]. Especially, patients diagnosed as low rectal tumors, and requested low anterior resection and anal retention technique were reported to be associated with the highest risk of anastomotic stricture at nearly 20\% [4]. Besides, postoperative anastomotic leakage, infection, disuse and postoperative radiotherapy can usually cause postoperative anastomotic strictures (PAS) in rectal cancer surgery[1,5]. PAS will result in defecation, and even severe intestinal obstruction, which seriously influences the long term quality of life of patients.

There have been many reports of kinds of treatments for these complications before[6-8]. Bipolar plasma kinetic vaporization resection is a newly developed technique and mainly used to treat benign prostatic hyperplasia currently. Compared with standard transurethral resection of prostate, the technique has been demonstrated with an improved efficacy in haemostasis[9, 10]. Also, it has advantages in aspects of its minimally invasion, repeatable and safety. While rare report on the use of the procedure of bipolar plasma kinetic vaporization resection for treating rectal anastomosis strictures by cutting the scars, especially for the type of hyperplastic scars related space occupying strictures. The objective of 
this report was to present the treatment outcomes of a case series of 12 PAS patients underwent bipolar plasma kinetic vaporization resection.

\section{Methods}

After approval from the IRB of The First Hospital of Jilin University,the data of 12 PAS patients underwent bipolar plasma kinetic vaporization resection after rectal cancer surgery in the First Hospital of Jilin University from February 2015 to December 2017 were retrospectively analyzed.

\section{General Information}

There were 11 males and 1 females, and 11 the patients adopted radically rectal resection by laparoscopy and prophylactic ileostomy. Postoperative transverse colostomy was performed in 1 cases because of delayed rectal vaginal fistula and pelvic infection. Eight of these patients received preoperative radiotherapy and three chemotherapy treatments. 3 months after rectal surgery, anastomotic stricture was detected by imaging and endoscopy before stoma rejection. Postoperative CT scan of one case showed that the rectal tube was narrow after rectal cancer surgery (Fig. 1). Anal finger examination was performed, with findings of an obvious narrow ring and failure of passing a finger. The length of stricture segment was 2 to $5 \mathrm{~cm}$ (mean, $3.5 \mathrm{~cm}$ ) by colonoscopy, with a diameter of 0.5 to $1 \mathrm{~cm}$ and a distance of 3 to $7 \mathrm{~cm}$ from the anus (Table 1). Preoperative examination confirmed none of recurrence and ileostomy return is performed after treatment. 
Table 1

General information of the 12 patients underwent bipolar plasma kinetic vaporization resection for rectal anastomotic strictures

\begin{tabular}{|ll|}
\hline Parameters & Value \\
\hline Sex $(\mathrm{n}, \mathrm{M} / \mathrm{F})$ & $11 / 1$ \\
\hline preoperative radiotherapy $(\mathrm{n})$ & \\
\hline Yes & 8 \\
\hline No & 4 \\
\hline Diameter of strictures (cm) & $0.5-1$ \\
\hline Length of strictures (cm) & $2-5$ \\
\hline Prophylactic ileostomy (n) & 6 \\
\hline Postoperative transverse colostomy (n) & 4 \\
\hline Time of vaporization (hours, range) & $0.5(0.26-1.25)$ \\
\hline Time of treatment (n, 1/2/3/4) & $8 / 3 / 0 / 1$ \\
\hline M: male; F: female; TME: total mesorectal excision. \\
\hline
\end{tabular}

\section{Bipolar Plasma Kinetic Vaporization Resection Procedure}

Under general anesthesia, lithotomy position was taken and the catheter was indwelling. The perineal and rectal areas were disinfected and sterile. Anal expansion, the distance from the anus, the diameter and the length of the strictures were explored (Fig. 2). LCAR STORZ urethroscopic operating system was connected. Anal canal was indwelling, and balanced salt electrocutting solution was infused. Wolf electric resectoscope and ring electric cutting ring (with cutting power $120 \mathrm{~W}$, coagulation power $80 \mathrm{~W}$ ) was utilized. Bipolar plasma kinetic vaporization resection was performed by sequentially removing scar ring on the surface until normal tissue, the wound was electrocoagulated to stop bleeding, and the original strictures were also dilated (Fig. 3). Intro-operative anal finger examination was routinely performed to clear the operation condition, the operation was completed until two fingers can pass by the stricture area (achieved a diameter about 4 to $4.5 \mathrm{~cm}$ ). The scar tissue was collected for pathology confirmation. Patients received anal expansion to prevent scar formation in every 2 to 3 weeks for 3 months until exhaust and defecation functions restored to a satisfactory state. Figure 4 showed the dilated bowel after surgical removal of scar tissue from the stricture.

\section{Outcomes And Follow-up}


All the patients were successfully treated by bipolar plasma kinetic vaporization resection. Postoperative pathology confirmed no cancer cells in the scar tissue. As shown in Table 1, the operation time was 0.26 to 1.25 hours (median, 0.5 hour). Patients were followed up at postoperative 1, 3, 6 months, and every 6 months thereafter until Dec 2017. Complications including venting, defecation and recurrence of stricture were monitored. No procedure related complications was found. Among them 3 cases received additional 1 resection and 1 cases received additional more than 3 resections(the patient with fistula and pelvic infection was ineffective )

\section{Discussion}

Rectal cancer is the fourth leading causes of cancer-related death around the world[11]. Along with the advance of low anterior resection and anal retention technique for rectal cancer, the incidence of anastomotic strictures is unavoidable to be increasing. Male patients diagnosed as low rectal cancer adopted low anterior resection and stapled anastomosis, sometimes also adopted prophylactic ileostomy would be associated with the highest risk of anastomotic strictures (about 20-30\%) in the population of the rectal cancer[12]. Risks of strictures occurrence mainly located at surgery and anastomosis related aspects. First, in our study 11 cases received prophylactic ileostomy, which was usually to be performed for emergency patients with symptom of intestinal obstruction under high risk of anastomotic leakage[13], however, it would lead to useless related strictures when routine anal expansion was absent.

Local tumor recurrence, radiotherapy and anastomotic technique related factors such as improper stapler size and anastomosis site were also frequent causes of postoperative strictures[14]. Certain methods were encouraged to be adopted to prevent anastomotic stricture occurrence, and if happened[15-17], it was clear that the treatment of rectal strictures should be based on its specific cause and symptom (defecation difficulty, about $5 \%$ in overall)[14]. In the current analysis, we mainly discussed the surgery and anastomosis related strictures. For these patients, anal expansion was firstly recommended, such as finger and/or instrument anal expansion weekly or every 2 to 3 weeks. Then, endoscopic techniques were advised for non-responders of expansion cases. As an effective method for most gastrointestinal disease, detailed information on stricture size, length, diameters, distance from the anus can be achieved under a direct vision[18]. Endoscopic balloon dilation, stent placement and also scar incision were all effective methods[19-21]. Finally, colostomy was only suitable for patients suffered severely obstructive symptoms.

Besides, we developed a new method by using bipolar plasma kinetic vaporization resection. It is an effective method for benign prostatic hyperplasia with small trauma, quick recovery, repeatability and good hemostasis[10]. Based on our experience in the 12 PAS, it presented similar advantages in above aspects, and also it had obviously advantages in its minimally invasion, repeatable treatments (when insufficient efficacy and recurrence occurred) and satisfactory haemostasis compared with other method and surgery through rectal speculum or endoscopy. However, this technique applied for rectal anastomotic strictures was only reported by our single center experience based on limited sample size. Although no bipolar plasma kinetic vaporization resection related complications was found, it should be 
performed with helps of a urologist. With experience in laparoscopic surgery, its training and learning curve would be short, and the key point was to carefully identify the border between scar and normal tissue. Also, additional anal expansion was still necessary to achieve the sustained efficacy. Compared with the other method, especially endoscopic dilation (which was frequently adopted in the clinic), our reported technique required general anesthesia. This contributed significantly decreased discomfort during treatment, whereas the cost and risk of anesthesia of course increased although comparative studies regarding their efficacy and safety were warranted. Meanwhile, for patients selection, this technique appeared to be more suitable for patients with hyperplastic scar with obvious space occupying findings or refractory benign strictures [22], whom may be hard to be treated by endoscopic methods. Thus, it may be deserved as an alternative and complementary option for non-responders of endoscopic methods. However, for the special I case, we can dig out that the therapeutic effect can only be maintained for a period of time, and then resumed in the past, Considering the patient's previous combined fistula and pelvic infection to stimulate the repeated growth of the scar, this patient May not apply to this technique.

\section{Conclusions}

when applying bipolar plasma kinetic vaporization resection technique in the treatment of postoperative rectal anastomotic stricture, it presented obvious advantage with conventional surgery. As a newly developed method, there are rare publications unless our single center experience. The indications, scope and comparative efficacy of the procedure remains unclear, which deserves further large-scale and well designed case-control and randomized controlled trials.

\section{Declarations}

\section{Ethics approval and consent to participate}

All procedures performed in this study involving human participants were in accordance with the ethical standards of the Ethics Committee of the First Hospital of Jilin University. Informed consent was waived in the study.

\section{Consent for publication}

Not applicable.

\section{Availability of data and materials}

The data that support the findings of this study are available from the corresponding author on reasonable request.

\section{Competing interests}

The authors declare that they have no competing interests. 


\section{Funding}

No funding.

\section{Authors' Contributions}

SPZ and MMX are responsible for writing and submitting the papers; SW is responsible for the data collection and analysis; YK and GQP are responsible for the production of pictures; WL are responsible for the ideas and guidance. The authors read and approved the final manuscript.

\section{Acknowledgements}

Not applicable.

\section{References}

1. Lee SY, Kim CH, Kim YJ, Kim HR. Anastomotic stricture after ultralow anterior resection or intersphincteric resection for very low-lying rectal cancer. Surg Endosc. 2018;32:660-6.

2. Warschkow R, Ebinger SM, Brunner W, Schmied BM, Marti L. Survival after Abdominoperineal and Sphincter-Preserving Resection in Nonmetastatic Rectal Cancer: A Population-Based Time-Trend and Propensity Score-Matched SEER Analysis. 2017, 2017:6058907.

3. MacRae HM, McLeod RS. Handsewn vs. stapled anastomoses in colon and rectal surgery: a metaanalysis. Dis Colon Rectum. 1998;41:180-9.

4. Marchena Gómez J, Ruiz de la Cuesta E, Gómez Guerra G, Vallejo Gallego I, García-Anguíano F. Hernández Romero JM: Anastomotic stricture with the EEA-Stapler after colorectal anastomosis. Rev Esp Enferm Dig. 1997;89:835-42.

5. Kumar A, Daga R, Vijayaragavan P, Prakash A, Singh RK, Behari A, Kapoor VK, Saxena R. Anterior resection for rectal carcinoma - risk factors for anastomotic leaks and strictures. World $\mathrm{J}$ Gastroenterol. 2011;17:1475-9.

6. Osera S, Ikematsu H, Odagaki T, Oono Y, Yano T, Kobayashi A, Ito M, Saito N, Kaneko K. Efficacy and safety of endoscopic radial incision and cutting for benign severe anastomotic stricture after surgery for lower rectal cancer (with video). Gastrointest Endosc. 2015;81:770-3.

7. Saxena P, Azola A, Kumbhari V, Kalloo AN, Khashab MA. EUS-guided rendezvous and reversal of complete rectal anastomotic stenosis after Hartmann's reversal. Gastrointest Endosc. 2015;81:4678.

8. Ragg J, Garimella V, Cast J, Hunter IA, Hartley JE. Balloon dilatation of benign rectal anastomotic strictures - a review. Dig Surg. 2012;29:287-91.

9. Geavlete B, Bulai C, Ene C, Checherita I, Geavlete P. Bipolar vaporization, resection, and enucleation versus open prostatectomy: optimal treatment alternatives in large prostate cases? J Endourol. 2015;29:323-31. 
10. Reich O, Schneede P, Zaak D, Siebels M, Hofstetter A. Ex-vivo comparison of the haemostatic properties of standard transurethral resection and transurethral vaporization resection of the prostate. BJU Int. 2003;92:319-22.

11. Ferlay J, Soerjomataram I, Dikshit R, Eser S, Mathers C, Rebelo M, Parkin DM, Forman D, Bray F. Cancer incidence and mortality worldwide: sources, methods and major patterns in GLOBOCAN 2012. Int J Cancer. 2015;136:E359-86.

12. Hiranyakas A, Da Silva G, Denoya P, Shawki S, Wexner SD. Colorectal anastomotic stricture: is it associated with inadequate colonic mobilization? Tech Coloproctol. 2013;17:371-5.

13. Yoo SB, Jeong SY, Lim SB, Park JW, Choi HS, Oh JH. Left-sided ileostomy at specimen extraction site in laparoscopic-assisted low anterior resection for rectal cancer. J Laparoendosc Adv Surg Tech A. 2013;23:22-5.

14. Schlegel RD, Dehni N, Parc R, Caplin S, Tiret E. Results of reoperations in colorectal anastomotic strictures. Dis Colon Rectum. 2001;44:1464-8.

15. Liu PC, Yan YK, Ma YJ, Wang XW, Geng J, Wang MC, Wei FX. Probiotics Reduce Postoperative Infections in Patients Undergoing Colorectal Surgery: A Systematic Review and Meta-Analysis. 2017, 2017:6029075.

16. Zhang YW, Wei FX, Qi XP, Liu Z, Xu XD, Zhang YC. Efficacy and Safety of Endoscopic Intralesional Triamcinolone Injection for Benign Esophageal Strictures. 2018, 2018:7619298.

17. Jain D, Singhal S. Esophageal Stricture Prevention after Endoscopic Submucosal Dissection. Clin Endosc. 2016;49:241-56.

18. Chen Q, Yu Q, Yu JJ, Liu M, Xie HP, Cheng B, Guao QZ, Liao GQ, Qin H. Observational study of colonoscopy techniques used for acute colorectal obstruction: A single-center experience. Mol Clin Oncol. 2017;6:355-61.

19. Morar PS, Faiz O, Warusavitarne J, Brown S, Cohen R, Hind D, Abercrombie J, Ragunath K, Sanders DS, Arnott I, et al. Systematic review with meta-analysis: endoscopic balloon dilatation for Crohn's disease strictures. Aliment Pharmacol Ther. 2015;42:1137-48.

20. Abbas MA. Endoscopic management of acute colorectal anastomotic complications with temporary stent. Jsls. 2009;13:420-4.

21. Matsuoka K, Inoue M, lida S, Tomiyasu K, Noda S. Endoscopic antegrade laser incision in the treatment of urethral stricture. Urology. 2002;60:968-72.

22. Siersema PD, de Wijkerslooth LR. Dilation of refractory benign esophageal strictures. Gastrointest Endosc. 2009;70:1000-12.

\section{Figures}




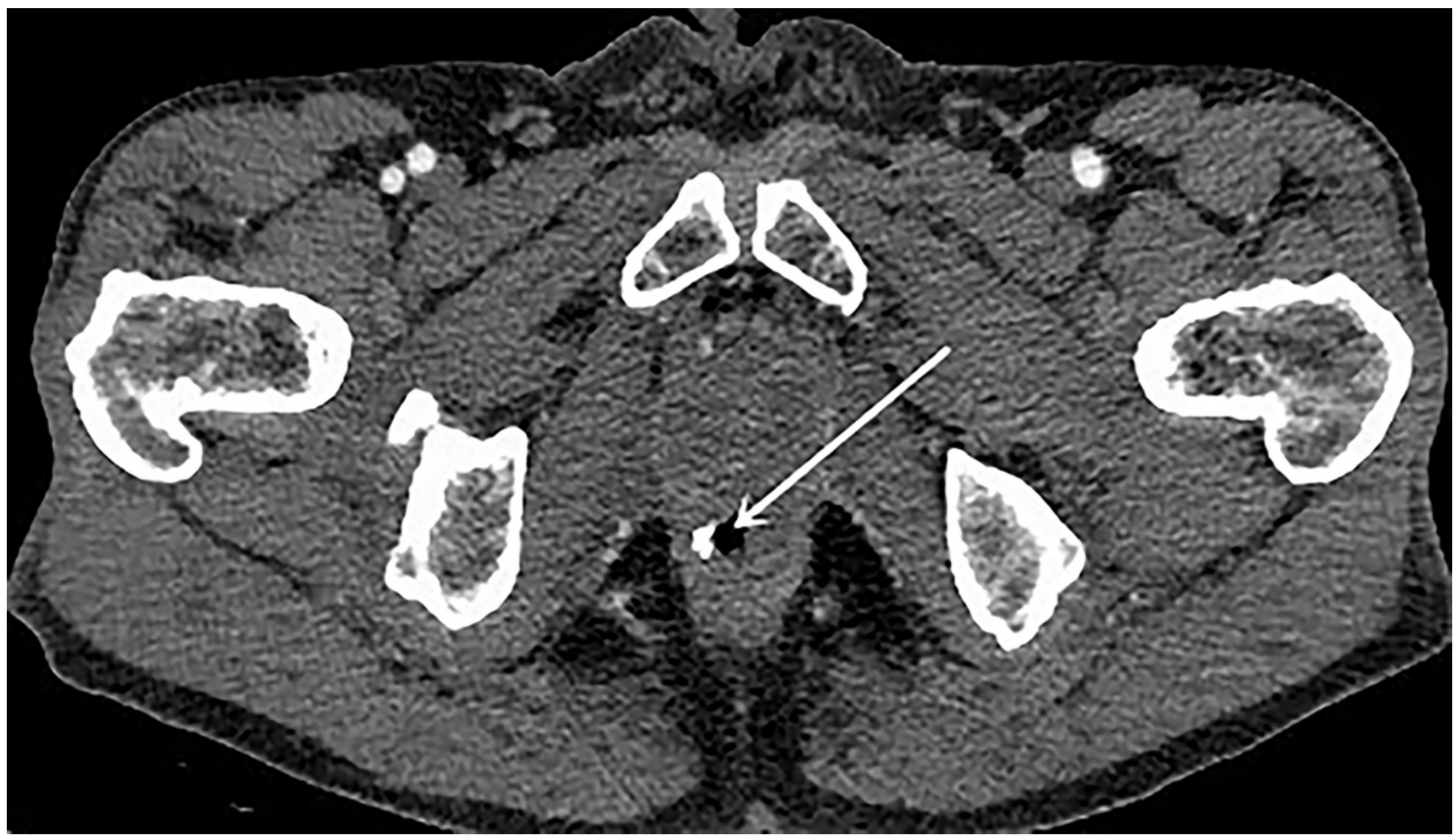

Figure 1

Postoperative CT scan showed that the rectal tube was narrow with moderate density of space occupying lesion located in the left side, indicating the occurrence of rectal anastomotic strictures after rectal cancer surgery. 


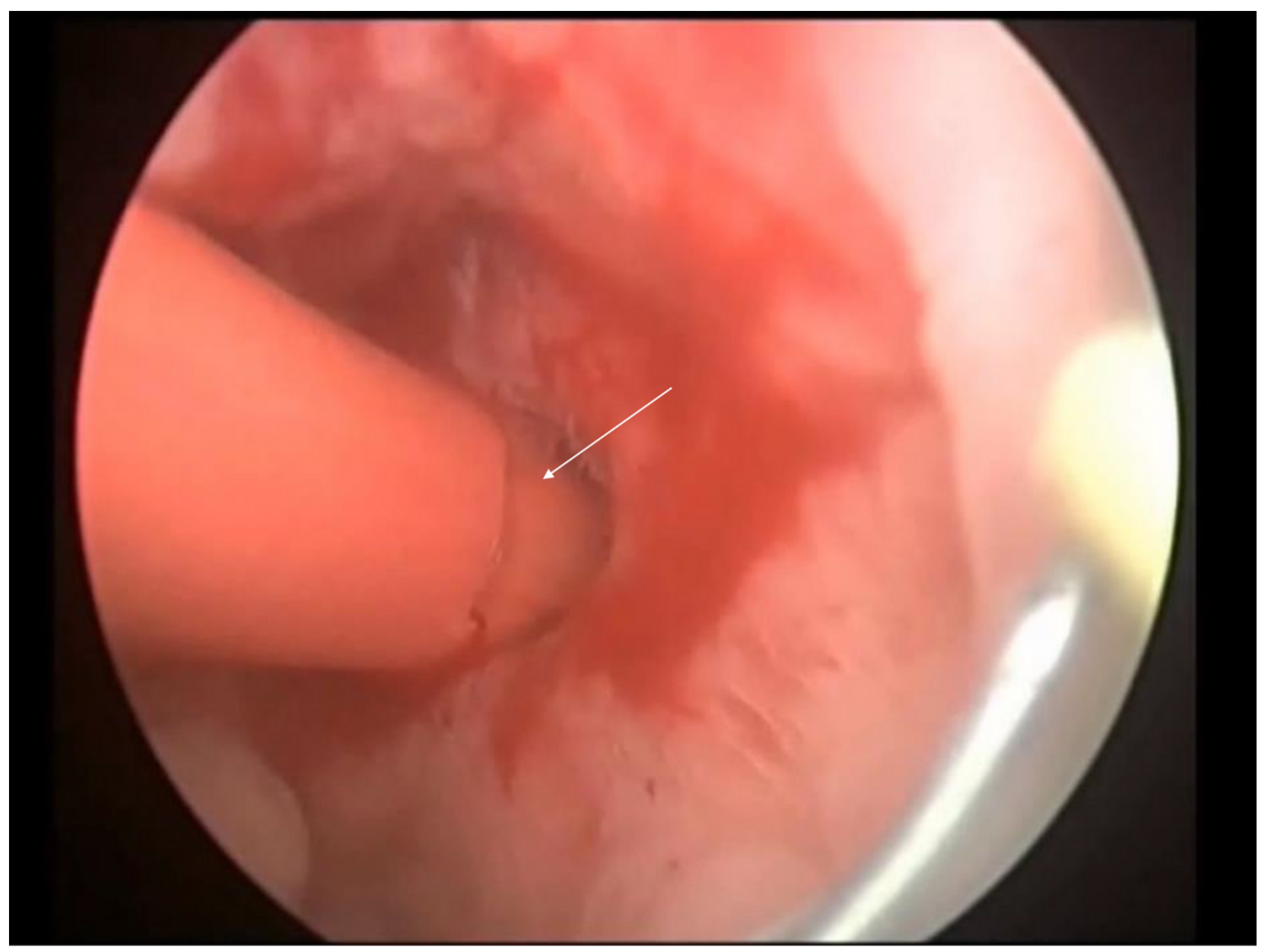

Figure 2

Urethroscopy showed that a significant anastomotic stricture located in the rectal tube leading to a about $1 / 3$ narrow site because of space occupying scars. The Arrow indicates that the finger can not pass through the narrow ring. 


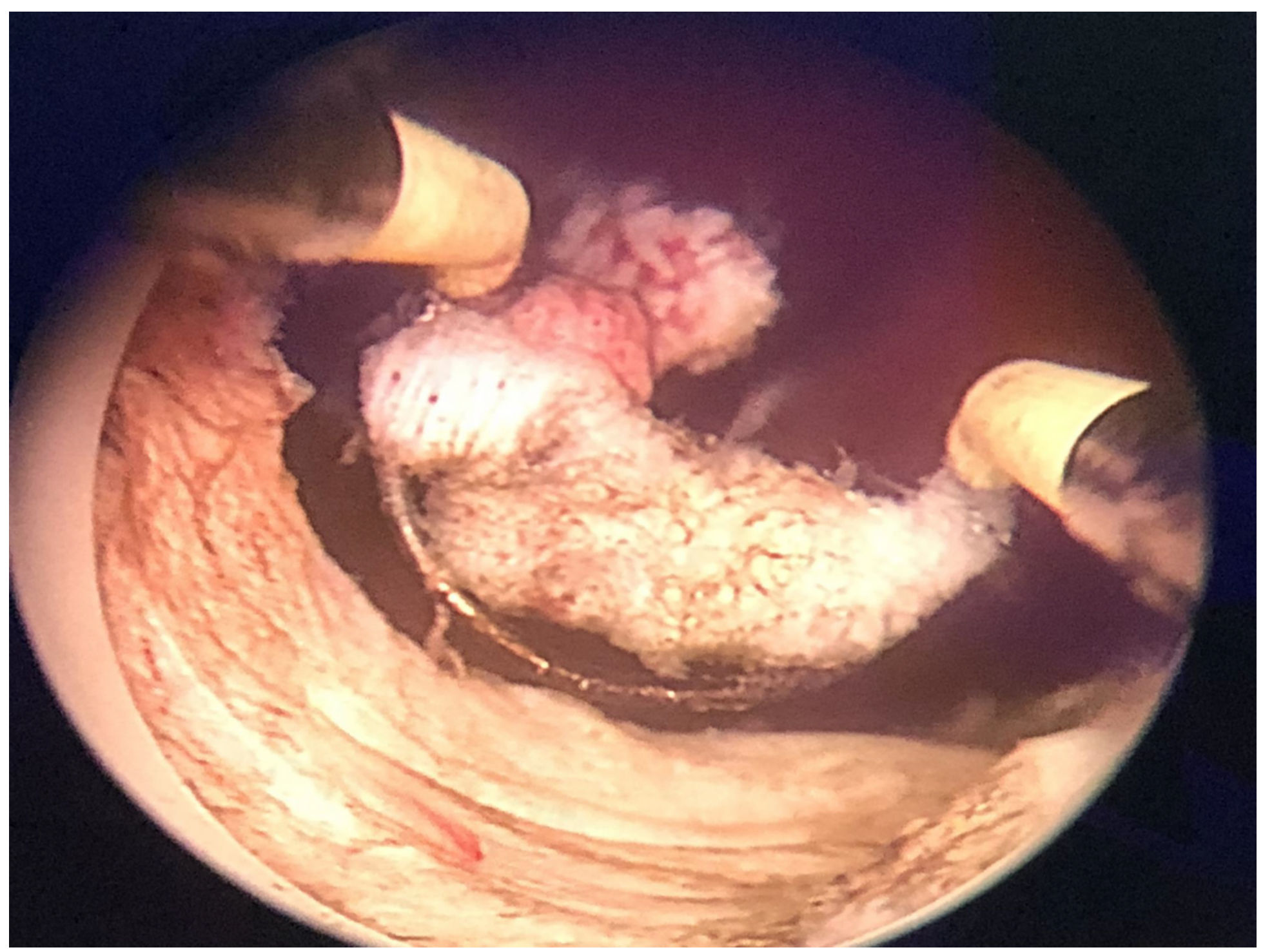

\section{Figure 3}

Bipolar plasma kinetic vaporization resection technique was applied to remove the hyperplastic scar of anastomotic stricture until normal tissue. The scar tissue was routinely collected for pathology confirmation. 


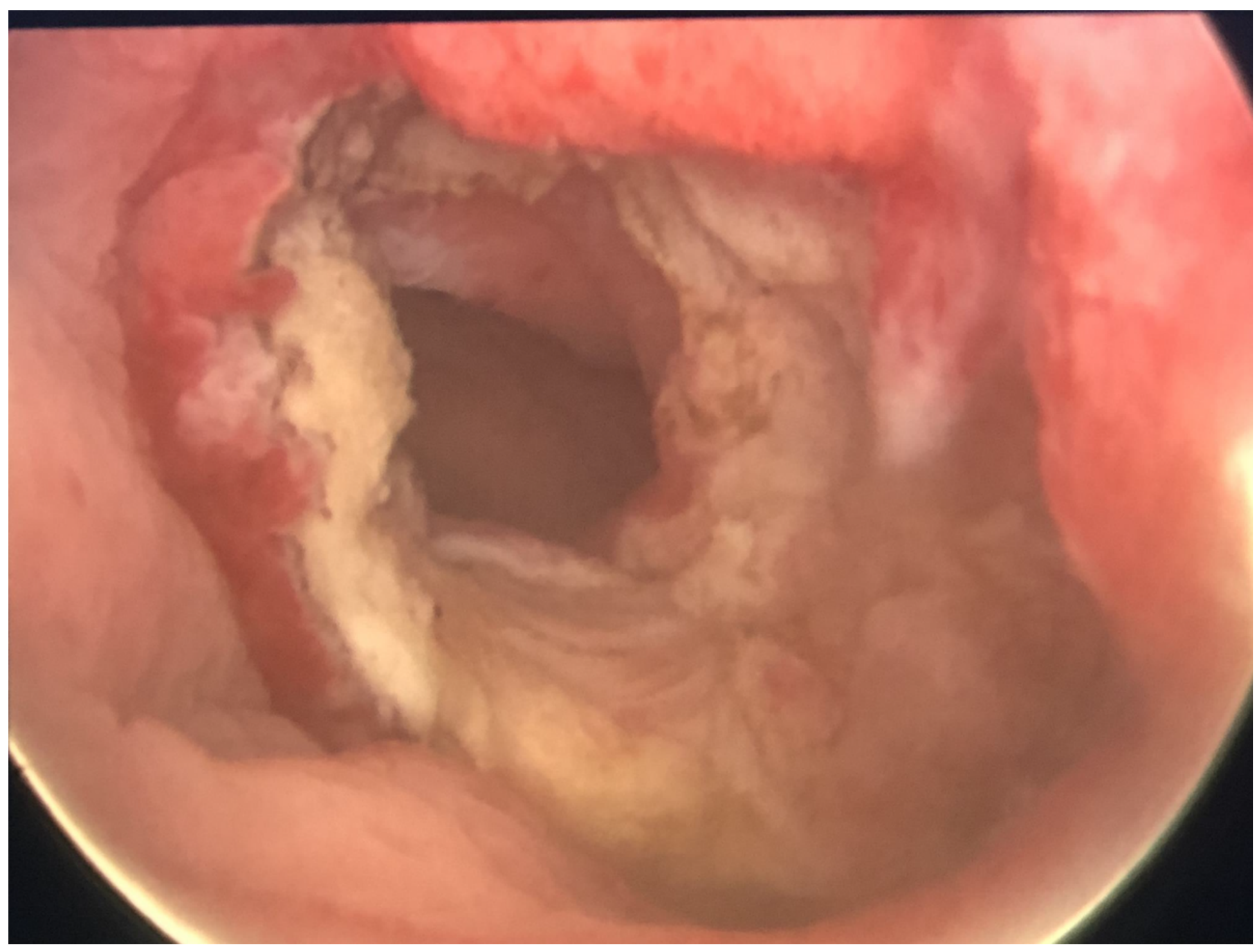

Figure 4

The dilated bowel after surgical removal of scar tissue from the stricture. 